Saint Louis University School of Law

Scholarship Commons

All Faculty Scholarship

Spring 2011

\title{
Implementing Health Reform at the State Level: Access and Care for Vulnerable Populations
}

John V.Jacobi

Seton Hall Law School

Sidney D. Watson

Saint Louis University School of Law Center for Health Law Studies

Robert Restuccia

Boston University School of Public Health

Follow this and additional works at: https://scholarship.law.slu.edu/faculty

Part of the Health Law and Policy Commons

\section{Recommended Citation}

John V. Jacobi, Sidney D. Watson, \& Robert Restuccia (2011). Implementing Health Reform at the State Level: Access and Care for Vulnerable Populations. Journal of Law, Medicine \& Ethics, pp. 69-72.

This Article is brought to you for free and open access by Scholarship Commons. It has been accepted for inclusion in All Faculty Scholarship by an authorized administrator of Scholarship Commons. For more information, please contact erika.cohn@slu.edu, ingah.daviscrawford@slu.edu. 


\title{
Implementing Health Reform at the State Level: Access and Care for Vulnerable Populations
}

\author{
John V. Jacobi, Sidney D. Watson, and Robert Restuccia
}

\section{Introduction}

The Affordable Care Act ${ }^{1}$ (ACA) promises to improve access to coverage and care for two vulnerable groups: low-income persons who are excluded by a lack of resources and chronically ill and disabled people who are excluded by the dysfunction of our existing insurance and care delivery systems. ACA's sprawling provisions raise a wealth of implementation challenges that are exacerbated by the compromises required to move reform through Congress. In particular, the compromise between regulatory/public program advocates and advocates for private, market-driven programs requires thoughtful regulatory coordination between public and private health systems.

The anticipated increase in coverage is roughly split between expansions in Medicaid and private enrollment, each of which is projected to cover approximately 16 million Americans. ${ }^{2}$ How ACA will be implemented has been the subject of constant attention since its enactment, and federal regulators have been generating program and regulatory information with commendable assiduity. However, state-level reform will be crucial to the effectiveness of the ACA implementation for low-income and chronically ill people. Federal structural regulations will be implemented and interpreted at the state level. As learned from the varied implementation of Medicaid and other state/ federal programs, state efforts can either effectuate or frustrate the intent of health coverage measures. This

John V. Jacobi, J.D., is the Dorothea Dix Professor of Health Law E' Policy at Seton Hall Law School. Sidney D. Watson, J.D., is a Professor of Law in the Center for Health Studies at Saint Louis University School of Law. Robert Restuccia, M.P.A., is the Executive Director of Community Catalyst and an Adjunct Professor at Boston University School of Public Health. article is focused on five key implementation issues states face as they turn to new tasks in the governance of Medicaid and private non-group and small group coverage. The Medicaid reforms and the extension of private coverage through Exchanges raise separate challenges. However, as described here, many key implementation issues apply to both systems.

\section{Five Key Issues Facing the States:}

\section{Coordinating Public and Private Expansion} Enrollment and Retention

ACA Section 2001 clears away barriers to Medicaid enrollment for non-elderly Americans. It extends eligibility to most people with incomes up to 133 percent of the federal poverty level. It also eliminates the asset test for most enrollees, a rule that disqualified those with savings of as little as $\$ 1,000$ to $\$ 3,000 .^{3} \mathrm{It}$ largely does away with confounding "categorical eligibility" requirements, simplifying the enrollment of low-income people. Sections 1401 and 1402 describe a system of refundable tax credits and out-of-pocket cost limitations to enable those up to 400 percent of the poverty level to afford private coverage offered through the Exchanges. This two-part structure marries private and public coverage systems in a way that should allow health insurance access for most people with existing financial barriers to coverage.

Eligibility does not assure enrollment, however, as we have learned from experience with Medicaid and the State Children's Health Insurance Program (SCHIP) programs. Many of today's uninsured children are eligible for either Medicaid and SCHIP coverage, but either have never enrolled or lost coverage. This failure to enroll and retain eligible children has been attributed in part to needless bureaucratic barriers. ${ }^{4}$ The lesson is that just creating a system of 
coverage is not enough. Good state practices and conscientious follow-up on a case-by-case basis are necessary to get historically disadvantaged people into the health care system.

ACA anticipates these problems. Sections 1413 and 2201 require the creation of a "no wrong door" enrollment system, seamlessly evaluating applicants for all public and private options. As Medicaid history makes clear, this coordination can either be done well or poorly at the state level. Anticipating the need for community assistance, ACA Section 1311 provides funding for, and obliges the state creation of, a community "patient navigator" in order to facilitate enrollment and provide community education.

\section{Coverage}

Research on health systems and bankruptcy has shown that underinsurance can be as significant a problem for individuals as uninsurance. ${ }^{5}$ ACA addresses the content of coverage for classes of new enrollees in private insurance and Medicaid. Section 1302 requires that private insurance offered through the Exchanges provide listed categories of "essential health benefits." Under Section 2001, most newly eligible Medicaid enrollees must receive "benchmark or benchmarkequivalent" coverage including, at a minimum: (1) the same essential health benefits that must be offered by private insurers; (2) transportation to and from necessary medical services; (3) Early and Periodic, Screening, Diagnosis, and Treatment Services for children; and (4) coverage of services provided by federally qualified health centers and rural clinics. ${ }^{6}$ States may opt to provide new Medicaid enrollees with benchmark coverage that includes additional Medicaid covered services not typically offered by private insurance, including full Medicaid coverage. ${ }^{7}$ Forthcoming federal regulatory guidance on the scope of the "essential health benefits" will be binding on all private insurance sold through the Exchanges. However, states will play the critical role in determining the benefit package for those newly eligible for Medicaid.

\section{Exchanges}

Exchanges, to be created by the states by 2014, will receive some funding and regulatory oversight from the federal Department of Health and Human Services (HHS) pursuant to Section 1311. The Exchanges will, in turn, be important regulators. Although the criteria for qualified health plans will be set by HHS, they will be applied by the Exchanges, which may certify a health plan for participation if it meets federal criteria. The Exchanges must consider each plan's justification for its premium history, ${ }^{7}$ and they must determine whether a plan's participation is "in the interest of qualified individuals and qualified employers." The Exchanges will base their determinations in part on yearly reports on claims and denial information supplied to them by health plans seeking certification. ${ }^{9}$ The Exchanges will then be empowered to consider the quality of plans' provider networks, their utilization control experience, and other factors essential to members' access to care, when making certification decisions. Determining what entity shall act as the Exchange and the operating philosophy of that entity will therefore, be an important implementation decision for each state. Deciding to treat the Exchange as a passive pass-through will frustrate ACA's reforms. Conversely, empowering the Exchanges to enforce market protections will go a long way toward securing ACA reforms.

\section{Workforce Issues}

Even the most progressive state Medicaid offices, Exchanges, and participating plans will be hardpressed to connect enrollees to needed care, unless qualified health care providers are available to provide care. For example, workforce issues have arisen as a barrier to Massachusetts's prior health care reform efforts. ${ }^{10}$ The concern arises from two directions. First, physicians and dentists have long been reluctant to participate in Medicaid, in part due to low reimbursement rates. Second, physicians are increasingly reluctant to forego the benefits of specialty practice to pursue primary care practice. ACA Title V addresses this concern by including a number of programmatic and funding opportunities calculated to increase the supply of physicians (particularly in primary care), dentists, nurses, and allied health professionals.

Physicians in training should be encouraged to opt for primary care careers. However, there is increasing evidence that the barriers to expanding the number of primary care physicians are more complex than pure monetary concerns; physicians are also concerned with status, lifestyle, and other related issues. ${ }^{11}$ In addition, there is increasing evidence that non-physicians, including advanced practice nurse practitioners, are just as capable in many settings of providing many primary care services as are physicians..$^{12}$

Although ACA's measures may help, important work ahead involves state laws governing professionals' scope of practice. These laws may inhibit non-physicians' and non-dentists' ability to practice independently to provide essential health services typically provided by physicians and dentists in primary care, particularly for low-income insureds..$^{13}$ As new insureds seek primary care services, states may confront a shortage of primary care providers qualified to practice under current licensure laws. Recent 
work reviewing the performance of advanced practice nurse practitioners and dental hygienists suggests that states should revisit laws limiting the scope of practice of non-physicians and non-dentists.

\section{Chronic and Long Term Care}

ACA's chronic care reforms recognize the confluence of many strains of research urging a shift from procedure-based fragmented care to patient-centered coordinated care for people with chronic illnesses and disabilities. ${ }^{14}$ Many of the ACA's Medicaid provisions are optional, allowing states to draw down federal funding to improve chronic care capacity - but also allowing them to decline to do so. For example, Section 2401 allows states to establish a program modeled on the Community First Choice program, which has successfully provided community support services for beneficiaries with disabilities (including those with cognitive disabilities) to permit community living and to avoid institutionalization. Section 2403 continues the Money Follows the Person Rebalancing Demonstration, a program that facilitates the deinstitutionalization of people with chronic illness and disabilities by permitting them to use Medicaid resources to obtain needed community support services. Under Section 2703 , states can also create "health homes" for people with chronic conditions, allowing for innovative coordinated care delivery for vulnerable populations. In addition, Section 2402 expands the usefulness of states' Home and Community Based Services (HCBS) programs significantly. Among other changes, it permits states to expand income levels for eligibility for HCBS participation, and greatly expands the "wrap around" services that can be made available to HCBS participants..$^{15}$ These services include "case management, homemaker/home health aide, personal care, adult day health, habilitation, and respite care services. To the extent states accept these options, they will gain federal funding support for improved Medicaid services for people with chronic illness and disabilities.

For people newly insured through the Exchanges, ACA offers the potential for improved coordination of chronic care. Section 1302, for example, defines "essential health benefits" to include both chronic disease management and habilitative care - i.e., care that maintains functioning but does not cure a disease or restore a patient following an injury. Including habilitative care within essential health benefits may improve care dramatically for people with chronic illness and disabilities because such care is covered poorly or not at all by most private insurance plans. ${ }^{16}$ How robustly these provisions will extend needed services depends in part on the federal regulatory elabo- ration of the terms, but also on state-level oversight of health plans operating through the Exchanges.

\section{Advocacy in State Implementation}

States are actively engaged in implementation of early aspects of health reform and are collaborating to share insights and establish best practices. ${ }^{17}$ Advocates, clinicians, citizens' groups, and engaged individuals have a role to play as states make key decisions described above. Critical functions that states may consider within this process include: ${ }^{18}$

- Help to educate the public on the unfolding benefits of health reform. As provisions of the ACA take effect, advocates can assist in implementation by ensuring that constituent groups are aware of new opportunities to gain health care and coverage.

- Provide expert analysis. States will be covering new ground as they implement modified forms of Medicaid and private coverage. For example, the injection of robust chronic care management and habilitative care into private insurance could be resisted in some cases. Clinical and public health experts and disability advocates can assist in implementation by helping to explain the importance of enhanced understanding of health insurance coverage. Similarly, as Medicaid programs consider the adoption of new tools to support community care for people at risk of institutionalization, community and expert input on the benefits of such a transition, from legal, clinical, and public policy perspectives, are needed.

- Assist in the coverage of newly eligible persons. Opportunities for coverage are often not taken, due to such factors as language/cultural barriers, bureaucratic complexity, or lack of knowledge of the new programs. Community groups and clinicians can help to provide a bridge between the state's efforts and the needs of vulnerable populations by, for example, facilitating enrollment at the point of care and providing linguistically and culturally fluent assistance at churches and community centers.

- Coordinate efforts among NGOs. Complex health reforms must draw on multiple areas of expertise of diverse organizations within states and nationally. Effective advocacy requires open communication and collaboration among groups with different competencies to assist the states in their implementation efforts, and to protect the interests of the vulnerable populations who are the intended beneficiaries of national health reforms. 


\section{References}

1. The Patient Protection and Affordable Care Act of 2010, Pub. L. No. 111-148, amended by Health Care and Education Reconciliation Act, Pub. L. No. 111-152, is commonly referred to as the Affordable Care Act.

2. See Congressional Budget Office, Letter from Peter Elmendorf to Nancy Pelosi, March 18, 2010, available at <http://www.cbo. gov/ftpdocs/113xx/doc11355/hr4872.pdf> (last visited December 10, 2010). The estimates in the letter did not take into account some small effects from the subsequent passage of the Health Care and Education Reconciliation Act.

3. See, V. Smith et al., "Eliminating the Medicaid Asset Test for Families: A Review of State Experiences," Kaiser Family Foundation, April 2001.

4. B. D. Sommers, "Why Millions of Children Eligible for Medicaid and SCHIP Are Uninsured: Poor Retention Versus Poor TakeUp," Health Affairs 26 (2007): w560-w567, at w563-w566.

5. M. D. Kogan et al., "Association between Underinsurance and Access to Care Among Children with Special Health Care Needs in the United States," Pediatrics 116 (2005): 1162-1169, at 11651167; E. Warren, "Bankrupt Children," Minnesota Law Review 86 (2002): 1003-1032, at 1020-1022.

6. ACA, \$2001(a)(2)(c); see, Letter from CMS State Medicaid Director, April 9, 2010, available at <https://www.cms.gov/ smdl/downloads/SMD10005.pdf> (last visited December 10, 2010), specifying the services that states must cover in benchmark coverage. Those exempt from mandatory enrollment in a benchmark plan include people who qualify for Medicaid because of disability, the medically frail, those dually eligible for Medicare and Medicaid, certain low-income parents, pregnant women, women who qualify for Medicaid because of break or cervical cancer, children in foster care or receiving adoption assistance, the medically needy, and individuals receiving only emergency services; ACA, §2001(a)(2).

7. 42 C.F.R. $\$ 440.330$ (2010).

8. ACA, $\$ \S 1311$ and 10104.

9. ACA, $\$ \$ 1311(\mathrm{e})(1)(\mathrm{b})$ and 10104(f)(2).

10. S. K. Long and P. B. Masi, "Access and Affordability: An Update on Health Reform in Massachusetts, Fall 2008," Health Affairs 28 (2009): w578-w587, at w582-583.
11. R. Steinbrook, "Easing the Shortage in Adult Primary Care - Is It All about Money?” New England Journal of Medicine 360 (2009): 2696-2699, at 2698 .

12. M. O. Mundinger et al., "Primary Care Outcomes in Patients Treated by Nurse Practitioners or Physicians," JAMA 283 (2000): 59-68, at 66-68.

13. M. J. Dueker et al., "The Practice Boundaries of Advanced Practice Nurses: An Economic and Legal Analysis," The Federal Reserve Bank of St. Louis, November 2005, available at $<$ https://research.stlouisfed.org/wp/2005/2005-071.pdf> (last visited December 10, 2010); L. Nolan et al., "The Effects of State Dental Practice Laws Allowing Alternative Models of Preventive Oral Health Care Delivery to Low Income Children," George Washington University Center for Health Services Research and Policy, January 17, 2003, available at <http:// www.gwumc.edu/sphhs/departments/healthpolicy/chpr/downloads/Oral_Health.pdf> (last visited December 10, 2010).

14. R. L. Kane et al., Meeting the Challenge of Chronic Illness (Baltimore: Johns Hopkins University Press, 2005): at 46-61.

15. Cindy Mann, Director CMS, State Medicaid Director Letter \#10-015 (August 6, 2010), available at <http://www.cms.gov. smdl/downloads/SMD10015.pdf>.

16. R. E. Benedict, "Disparities in Use of and Unmet Need for Therapeutic and Supportive Services among School-Age Children with Functional Limitations: A Comparison Across Settings," Health Services Research 41 (2006): 103-124, at 118.

17. National Governor's Association, Rx for Health Reform: Affordable, Accessible, Accountable, July 9, 2010 available at <http:// www.nga.org/Files/pdf/1007DELIVERYSYSTEMREFORM. $\mathrm{PDF}>$ (last visited December 10, 2010).

18. Community Catalyst, Building on the Foundation: Consumer Advocacy's Role in Successful Health Care Reform, April 2010 available at <http://www.communitycatalyst.org/assets/pdf/ Building_on_the_Foundation_Consumer_Advocacy_and Health_Reform_April_2010.pdf $>$ (last visited December 10, 2010). 